\title{
Goudge: "systemic failings" in Ontario coroner's office
}

\author{
Judge urges better training and standards for pathologists
}

$\mathrm{S}$ ystemic flaws and inattentive bosses made it possible for an unqualified pathologist to make critical errors that led to wrongful convictions and "devastating consequences" for parents of dead children, the judge heading an inquiry into botched autopsy cases in Ontario has concluded.

"The tragic story of pediatric forensic pathology in Ontario from 1981 to 2001 is not just the story of Dr. [Charles] Smith," Judge Stephen Goudge said in releasing his 1000-page report on Oct. 1.

"It is equally the story of failed oversight. The oversight and accountability mechanisms that existed were not only inadequate to the task, they were inadequately employed by those charged with using them."

Among the 160 recommendations Goudge made is one urging that the Royal College of Physicians and Surgeons of Canada develop an accredited training program for forensic pathologists. The College and the Canadian Association of Pathologists have sought national standards and quality assurance for pathologists (CMAJ 2008;179[2]:125-6 and CMAJ 2008;178[12]:1523-4).

Smith, who worked at Toronto's Hospital for Sick Children, was considered a "star" in pediatric pathology. He testified in dozens of criminal cases involving the deaths of children. Despite his reputation, Smith in fact was unqualified as a forensic pathologist and his training was "woefully inadequate," Goudge told reporters.

Smith shone in part because there was a severe shortage of forensic pathologists in the province that continues today, Goudge added. "The serious mistakes he made with the terribly unfortunate consequences that resulted were on clear display at the inquiry."

Ontario called the inquiry after a review determined Smith made serious errors in at least 20 cases, 12 of which led to criminal convictions of parents.

Goudge's report includes 169 recommendations aimed at restoring public confidence in the forensic pathology sys- tem. In response to the report, the province announced it will explore compensation for those wrongfully convicted on the basis of Smith's opinions and testimony. It will also investigate 220 cases involving "shaken baby syndrome."

"These are cases in which the science, the medical opinion, was based on a science that has evolved," said Ontario Attorney General Chris Bentley, pledging to ensure that in all cases where a conviction rested on deficient science, "any injustices are righted."

In some instances, Smith concluded children had been murdered when in fact no murder had occurred, as in a case involving William Mullins-Johnson, who spent 12 years in prison after courts were persuaded by Smith's testimony that the man's niece had been strangled and sexually assaulted under his watch. Smith's opinion later proved wrong.

In his report, Goudge criticized Smith's "sloppy and inconsistent" documentation, lack of relevant medical information, arrogance and failure to act on new information. He also dubbed Smith unprofessional for making "false and misleading statements to the court."

But Goudge also levelled blame at Smith's superiors, former chief coroner Dr. James Young and his deputy, Dr. James Cairns. "For far too long, Dr. Smith was not held accountable."

Both Young and Cairns ignored or dismissed complaints about Smith's work and "did far too little" about his mounting problems, Goudge said. In fact, the "symbiotic" relationships that existed among the men led Young and Cairns to protect Smith when his work was questioned.

Young's desire to protect the reputation of the Office of Ontario's Chief Coroner overshadowed any concern for victims of Smith's mistakes, Goudge added. "When he finally did act, it was to protect the reputation of the office, and not out of concern that individuals and the public interest may already have been harmed."

Goudge urged a number of systemic reforms to ensure that similar tragedies

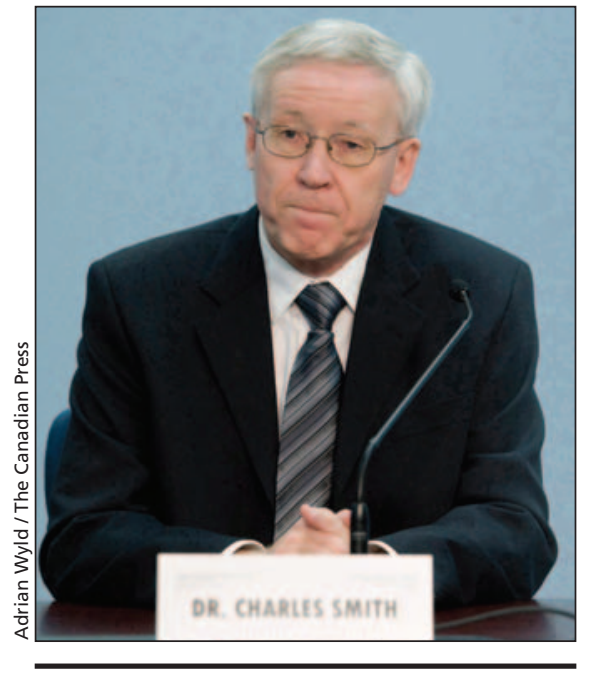

Discredited pathologist Dr. Charles Smith testifies in January 2008 at the Goudge inquiry into systemic errors in pediatric forensics within Ontario.

are avoided in the future. Those included:

- Amending the Coroner's Act to recognize the role of the forensic pathology service

- Creating the Ontario Forensic Pathology Service, led by a certified chief forensic pathologist

- Developing and accrediting training programs for forensic pathologists, through the Royal College of Physicians and Surgeons of Canada

- Adequately funding and equipping forensic pathology facilities

- Creating a registry of certified forensic pathologists

- Emphasizing an evidence-based culture where forensic pathologists "think truth" rather than "think dirty"

- Improving the inadequate delivery of pediatric forensic pathology services to First Nations and other remote communities in Northern Ontario.

Ontario Community Safety Minister Rick Bartolucci has promised to introduce new legislation to strengthen the death investigation system and improve oversight and accountability for coroner and pathology services in Ontario. - Laura Eggertson, Ottawa, Ont.

DOI:10.1503/cmaj.081625 